\title{
Early ureteric stent removal reduces urinary tract infection in kidney transplant recipients: A randomized controlled trial
}

\author{
Watanyu Parapiboon ${ }^{1}$, Keeratipon Wiengpon ${ }^{2}$, Chagriya Kitiyakara ${ }^{1}$, Bunyong Phakdeekitcharoen ${ }^{1}$, Charoen Leenanupunth ${ }^{2}$ \\ Kongchareonsombat Wisoot ${ }^{2}$, Sopon Jirasiritham ${ }^{2}$ and Vasant Sumethkul ${ }^{1 *}$ \\ ${ }^{1}$ Department of Medicine, Faculty of Medicine, Ramathibodi Hospital, Mahidol University, Bangkok, Thailand \\ ${ }^{2}$ Department of Surgery, Faculty of Medicine, Ramathibodi Hospital, Mahidol University, Bangkok, Thailand
}

\begin{abstract}
Background: Optimal duration for retaining ureteric stent after kidney transplantation was still controversy. We aimed to determine benefits and risks of early versus routine stent removal in kidney transplantation.

Methods: 90 patients who underwent kidney transplantation from April 2010-January 2011 were enrolled in single-center randomized controlled, open label, trial. Patients were randomized to early ureteric stent removal ( 8 day) or routine ureteric stent removal (15 day) groups. The primary outcome was rate of urinary tract infection (UTI) during postoperative to 1 week after discharge.

Results: 74 patients (58\% living donor) fulfilled the randomized criteria (early remove $n=37$; routine remove $n=37$ ). By intention to treat analysis, incidence of UTI in early stent removal was less than routine stent removal group $(15 / 37,40.5 \% \mathrm{VS} 27 / 37,72.9 \%$; Risk reduction $32.4 \%$; $95 \% \mathrm{CI} 11.1$ to $53.7 \%$, P = 0.004). The benefit of early ureteric stent removal is demonstrated mostly in living donor subgroup. Probability of UTI was significantly associated with the duration of stent retention. Incidence of urologic complications was not different in both groups.
\end{abstract}

Conclusions: Shortening duration of ureteric stent in kidney transplant recipients from 15 to 8 days is safe. This approach helps to reduce incidence of UTI particularly in living kidney transplantation (Funded by Thai Transplant Society; Trial registration ACTRN12610000310066).

\begin{abstract}
Abbreviations: UTI: Urinary tract infection
\section{Introduction}

Urinary tract infection (UTI), including pyelonephritis, lower tract cystitis and asymptomatic bacteriuria is the most common bacterial infection for kidney transplant recipients [1]. The incidence of UTI is still high, approximately $7 \%$ to $75 \%$ [2-5]. In UTI, not only urosepsis but also lower tract cystitis as well as asymptomatic bacteriuria are clinically important. Asymptomatic bacteriuria leads to increased urinary inflammation cytokine, and increased risk of upper tract infection [6,7]. All of these are associated with an increased mortality risk, septicemia, and decreased kidney graft function [3,5,8-10].
\end{abstract}

Risk factors of UTI in kidney transplant recipients are classified into pretransplant period peri-transplant period and post transplant period [9]. Ureteric stent is one of the risk factors that are modifiable. In addition, incidence of UTI is higher in cases of ureteric stent placement compared with no stent $[11,12]$. However, potential benefits of a ureteric stent are preventing ureteric obstruction and leakage $[12,13]$. The routine use of ureteric stent after kidney transplantation is still controversial. Due to high morbidity of urologic anastomosis complication, there is data that shows the cost-benefit of routine ureteric stent [14]. When ureteric stent is used, the optimal duration of stenting has not yet been clarified. The longer the stent is retained, the higher risk of UTI and complications arising from the stent, including migration, and the possibility of the stent being forgotten. The appropriate removal time will minimize the risk of UTI. In practice, the duration of stenting varies in each center varies from 3 days to 3 months [13,15-21]. Leaving a stent for a short period of time could reduce UTI but could increase the incidence of urologic complication, and vice versa.

Therefore we conducted a randomized controlled trial to find the appropriate stenting time in kidney transplantation to achieve a balance and minimize both UTI and urologic complications.

\section{Material and methods}

\section{Study design}

This was an open-label, single-center randomized controlled trial designed to determine the potential benefit and harmful of early ureteric stent removal compared with routine removal in kidney transplant recipients. A prior random number was calculated by using

Correspondence to: Vasant Sumethkul MD, Department of Medicine, Ramathibodi Hospital, 270 Rama 6 Road, Bangkok 10400, Thailand, E-mail: vasant.sum@mahidol.ac.th

Key words: kidney transplantation, ureteric stent, urinary tract infection, randomized control trial, living related donors

Received: November 17, 2016; Accepted: December 06, 2016; Published: December 09, 2016 
a computer-generated block of four. An allocation of 1:1 was achieved and the results concealed in an opaque, sealed envelop. This study was approved by the Institutional Review Board (IRB) of the investigating hospital.

\section{Patients}

Adult living and deceased kidney transplant recipients (age $\geq 18$ years) who receive transplantation during a ten month studied period were enrolled. Exclusion criteria were patients who had neurogenic lower urinary tract disease and abnormal structure of donated kidney. Also excluded were En bloc pediatric kidney donors and patients with cold ischemic times of more than 36 hours.

\section{Study protocol}

After obtaining an informed consent, the participants were randomized into two groups, early and routine stent removal. The early ureteric stent removal group retained the stent for 7 days postoperatively and for 14 days in the routine group. Primary outcome was incidence of UTI during the postoperative period up to 1 week after hospital discharge. Secondary outcomes were incidence of urologic complications (leakage and obstruction) postoperatively to 1 week after hospital discharge, incidence of positive ureteric stent culture, estimated GFR (eGFR) at hospital discharge and length of stay

\section{Surgical technique}

All donor nephrectomies were both open and laparoloscopic nephrectomy. Vascular anastomosis of kidney graft was revascularized by standard end to side technique. The ureterovesical anastomosis was done by extravesical Lich-Gregoir ureteroneocystostomy technique. The ureter-to-mucosa anastomosis was performed by Maxon 5-0 interrupted fashion and the bladder muscle was closed with interrupted sutures by chromic 3-0. Ureteric stent 6 French, $26 \mathrm{~cm}$ (Integral ureter stent set, WIRUTHAN ${ }^{\circ}$ ) was inserted after one side of the anastomosis was completed. The stent was endoscopically removed with a flexible endoscope at between $7^{\text {th }}$ or $14^{\text {th }}$ post-operative day under local anesthesia. In both groups, a bladder catheter was retained for 7 days.

\section{Immunosuppressive and antibiotic prophylaxis}

All patients received intravenous cefuroxime $750 \mathrm{mg}$ before surgery and continued for 3 doses in first day post-operative then Sulfamethoxazole/trimethoprim $(400 / 80 \mathrm{mg}) 1$ tab per day was given as antibiotic prophylaxis if the patient was not allergic. Immunosuppressive regimen was based on individual clinician judgment. This regimen consisted of triple therapy for maintenance (cyclosporine or tacrolimus, mycofenolate mofetil or myfortic and steroid). Steroid regimen was methylprednisolone intravenously 1000 $\mathrm{mg}$ in first day postoperatively then 500 and $250 \mathrm{mg}$ on the next two days respectively. Prenisolone was used by starting $60 \mathrm{mg}$ per day at postoperative day 4 then tapering off to $15 \mathrm{mg}$ per day in 1 month. Induction of Basiliximab or Anti-thymocyte globulin was used in some patients as clinically indicated.

\section{Diagnosis of UTI and urologic complication}

Routine urine examination and culture were undertaken at day 0 , $3,7,10,14$ post-operatively then twice a week until hospital discharge and first follow up after hospital discharge. The removed stent was sent to culture. UTI was classified into 3 groups specifically symptomatic UTI, asymptomatic UTI and urosepsis. Symptomatic UTI was defined by the presence of symptoms of fever or dysuria combine with the presence of pyuria (white blood cell $\geq 5$ cell per high power field) and bacteriuria (culture positive $\geq 10^{3}$ colony-forming unit (CFU) per ml of urine via bladder catheter or $\geq 10^{5} \mathrm{CFU}$ per $\mathrm{ml}$ of midstream. If positive blood culture had the same organism as in urine, it was classified as urosepsis. Patients who have significant bacteriuria ( $\left.\geq 10^{5} \mathrm{CFU}\right)$ but no other symptom was defined as asymptomatic bacteriuria. If UTI occurred, proper antimicrobial was given depending on culture. Clinical suspicions confirmed with imaging (ultrasonography and radioisotope scan) were used to diagnose ureteric obstruction or leakage. Ureteric leakage was suspected when there was an accumulation of urine around the graft or in the operative wound then confirmed by retrograde pyelogram or intraoperative findings. Ureteric obstruction was defined as impaired renal function with imaging showing pelvicaliceal dilatation and confirmed by antegrade nephrostogram. Moreover, Radioisotope scan was done to detect urologic complications at 1 to 2 months postoperatively and estimated GFR was calculated when discharged by 4 variable MDRD formulas [22].

\section{Statistical analysis}

Results were expressed as numbers, percentages, mean $\pm \mathrm{SD}$ or median \pm IQR. Chi-square or Fisher's exact was used to compare incidence of UTI, urologic complication between the two groups. To compare eGFR and length of stay between groups, Student's t test or Mann-Whitney U test were performed. Cox's proportional hazard model was used in multivariate analysis to determine risk factors of UTI. $\mathrm{P}<0.05$ was considered statistically significant. All statistical tests used STATA release 11 for calculation.

\section{Sample size calculation}

The sample size was calculated on the assumption that reduction in UTI would be from $54 \%$ to $27 \%$ between two intervention arms (routine stent removal vs. early stent removal group). The power of this study was at least $80 \%$ and alpha level of 0.05 . The calculated formula was based on two sided test for comparison of the two populations. The estimated rate of UTI of $54 \%$ in the routine stent removal group was based on preliminary data from our center, while reduction in UTI by $50 \%$ was clinically useful. Finally, the sample size was 76 participants for detecting difference of proportion between the two groups.

\section{Results}

A hundred and ten renal transplants were performed at our center during the study period. Seventy-four of 90 eligible patients (82\%) were enrolled to the study. The reasons for exclusion and Consolidated Standards of Reporting Trials (CONSORT) statements are shown in Figure 1.

In total, 74 patients were randomized to two groups: (I) routine stent removal group $(\mathrm{n}=37)$ or (ii) early stent removal $(\mathrm{n}=37)$ group. Three patients in the early removal group were switched to routine removal group. Therefore, we analyzed this data by using the intention to treat method. Median of stent duration was 8 days in the early removal group and 15 days in the routine removal group. The baseline characteristics were similar in each group (Table 1). The number of patients who received induction therapy was not different among the two groups.

Median follow up time was 31.5 and 29 days in group 1 and 2 respectively. Overall incidence of UTI was $56.7 \%$ during the study period (1430 patient-days at risk) that was 7.49 episodes per 100 patients a year. The most common form of UTI was symptomatic UTI (48\%) followed by asymptomatic bacteriuria (40\%). Incidence of urosepsis was $12 \%$ (Figure 2). E. coli $(40.4 \%)$ was the most common 


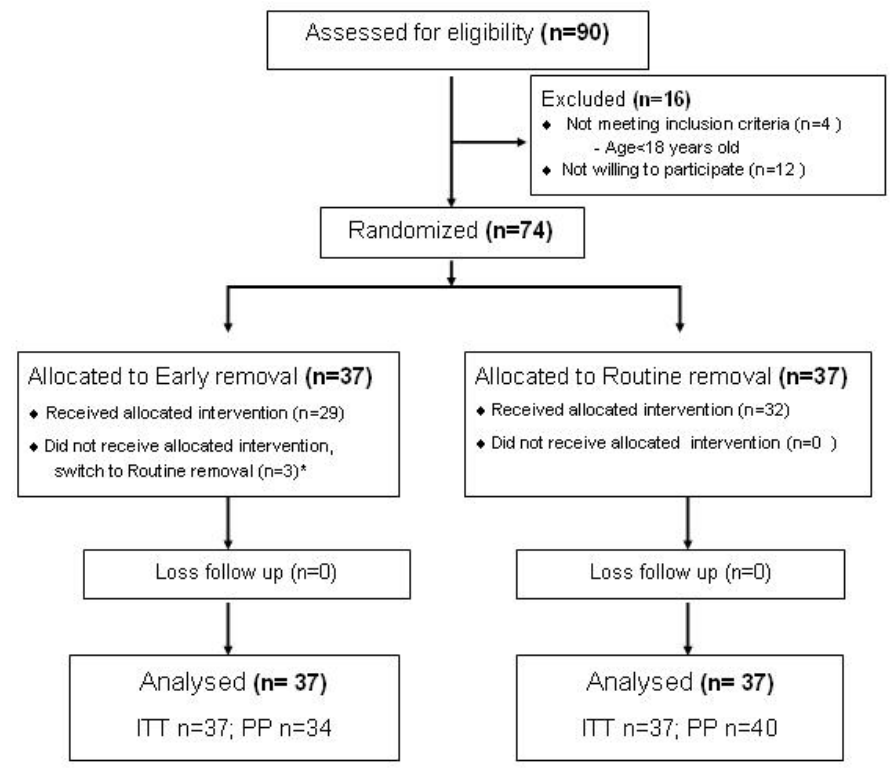

Figure 1. Study flow diagram as CONSORT statement. * 3 participants in early removal group switch to routine removal group due to drain $>100 \mathrm{ml} /$ day at post-operative day 6 . $\mathrm{ITT}=$ intention to treat; $\mathrm{PP}=$ per protocol.

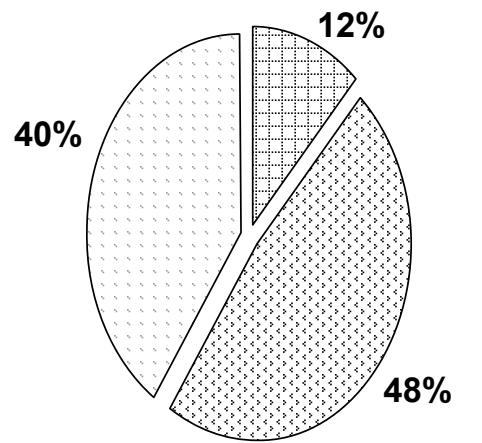

\section{.]. Urosepsis \\ Symptomatic UTI \\ Asymptomatic bacteriuria}

Figure 2. Type of UTI in 42 patients.

organism of UTI in this study. Other major organisms that caused UTI were Klebsiella pneumoniae (19.1\%), Stenotrophomonas (10.6\%), Enterococcus (10.6\%) and Pseudomonas aeruginosa (10.6\%). Incidence of Extended Spectrum Beta-Lactamase (ESBL) organisms, which consist of E. coli and Klebsiella pneumoniae, was 34\%.

UTI was diagnosed in 15 out of 37 patients (40.5\%) in the early removal group and 27 out of 37 patients $(72.9 \%)$ in routine stent removal group. Incidences of UTI in the two groups were statistically different (absolute risk reduction $=32.4 \%$; $95 \%$ CI 11.1 to $53.7 ; \mathrm{P}=$ 0.004 using intention to treat analysis and absolute risk reduction $=39.7 ; 95 \%$ CI 18.7 to $60 ; \mathrm{P}=0.0006$ in per protocol analysis). The calculated number needed to treat to see benefit of early stent removal for UTI reduction was 3.0 patients (95\%CI 1.8 to 9 ). Subgroup analysis revealed that the incidence of UTI was $22.7 \%$ and $66.6 \%$ in early and late stent removal group (Absolute risk reduction $=43.9 \%$; $95 \% \mathrm{CI}$ 17.2 to $70.6 ; \mathrm{P}=0.004$ ) for living kidney transplantation. However, the incidence of UTI was not significantly different among early and late stent removal group $(66.6 \%$ and $81.2 \%$, absolute risk reduction $=14.5 \% ; 95 \% \mathrm{CI}-15.9$ to $45.1 ; \mathrm{P}=0.35)$ in the recipients who receive deceased kidney transplantation (Figures 3 and 4).

Length of hospital stay was reduced in the early stent removal
Table 1. Baseline data of recipient and kidney graft.

\begin{tabular}{|c|c|c|}
\hline & Early (n=37) & Routine $(\mathrm{n}=37)$ \\
\hline \multicolumn{3}{|l|}{ Recipient } \\
\hline Age (years \pm SD) & $42.7 \pm 12.4$ & $43.8 \pm 14.1$ \\
\hline Male, n (\%) & $24(65)$ & $27(73)$ \\
\hline $\mathrm{DM}, \mathrm{n}(\%)$ & $9(24.3)$ & $6(16.2)$ \\
\hline Prior other antibiotic post-operative, $\mathrm{n}(\%)$ & $5(13.5)$ & $6(16.2)$ \\
\hline \multicolumn{3}{|l|}{ Cause of ESRD, n (\%) } \\
\hline -Diabetic nephropathy & $9(24.3)$ & $6(16.2)$ \\
\hline -Glomerulonephritis & $7(18.9)$ & $9(24.3)$ \\
\hline -Stone & $1(2.7)$ & $1(2.7)$ \\
\hline -Other & $3(8.1)$ & $5(13.5)$ \\
\hline -Unknown & $17(45.9)$ & $16(43.2)$ \\
\hline Preemptive transplantation, $\mathrm{n}(\%)$ & 0 & $3(8.1)$ \\
\hline Hemodialysis, n (\%) & $36(97.3)$ & $31(83.2)$ \\
\hline Peritoneal Dialysis, n (\%) & $1(2.7)$ & $3(8.1)$ \\
\hline Duration of dialysis, months (P25-P75) ${ }^{1}$ & $45(18-72)$ & $24(9-36)$ \\
\hline Body mass index $\left(\mathrm{kg} / \mathrm{m}^{2} \pm \mathrm{SD}\right)$ & $21.7 \pm 3.3$ & $22.1 \pm 3.3$ \\
\hline Body surface area $\left(\mathrm{m}^{2} \pm \mathrm{SD}\right)$ & $1.63 \pm 0.18$ & $1.63 \pm 0.20$ \\
\hline Living donor, $\mathrm{n}(\%)$ & $22(59.4)$ & $21(56.7)$ \\
\hline Decease donor, $\mathrm{n}(\%)$ & $15(40.5)$ & $16(43.3)$ \\
\hline For decease donor & 15 & 16 \\
\hline -Cold ischemic time (hour.minnute \pm SD) & $20.01 \pm 5.42$ & $19.09 \pm 4.28$ \\
\hline -Extended criteria donor, $\mathrm{n}(\%)^{2}$ & $3(20 \%)$ & $3(18.75 \%)$ \\
\hline -Last Cr before harvest, $\mathrm{n}(\%)$ & $2.26(1.33)$ & $1.83(1.29)$ \\
\hline -Graft pyuria, $n(\%)^{3}$ & $5(13.5)$ & $5(13.5)$ \\
\hline High immunologic risk ${ }^{4}$ & $8(21.6)$ & $10(27)$ \\
\hline Chronic hepatitis B infection in recipient, $\mathrm{n}(\%)$ & $3(8.1)$ & $1(2.7)$ \\
\hline \multicolumn{3}{|l|}{ Immunosuppressive, $\mathrm{n}(\%)$} \\
\hline -ATG & 0 & $1(2.7)$ \\
\hline -Anti-IL2 & $14(37.8)$ & $13(35.1)$ \\
\hline \multicolumn{3}{|l|}{ Maintenance, n (\%) } \\
\hline -Cyclosporine-based & $17(46)$ & $20(54)$ \\
\hline -Tacrolimus-based & $20(54)$ & $17(46)$ \\
\hline Duration of bladder catheter, days $(\mathrm{P} 25-\mathrm{P} 75)^{1}$ & $7(7-7)$ & $7(7-7)$ \\
\hline Stent duration, days $(\mathrm{P} 25-\mathrm{P} 75)^{1}$ & $8(1,1)$ & $15(1,1)$ \\
\hline Trimethoprim/sulfamethoxazole prophylaxis, $\mathrm{n}(\%)$ & $37(100)$ & $37(100)$ \\
\hline
\end{tabular}

Baseline data were similar between 2 group $(\mathrm{P}>0.05)$

${ }^{1}$ Median $\left(25^{\text {th }}\right.$ percentile- $75^{\text {th }}$ percentile $)$; ${ }^{2}$ Donor age $\geq 60$ years old or $>50$ years with the following 2 of 3 (hypertension, death from cerebrovascular disease and serum creatinine $>1.5 \mathrm{mg} / \mathrm{dl}$ ); ${ }^{3}$ White blood cell $>10$ /high power field on urinary analysis; ${ }^{4}$ Lymphocyte crossmatch positive IgM or PRA $>20$ or HLA mismatch 6 in $6 \mathrm{SD}=$ standard deviation

\section{Overall UTI}

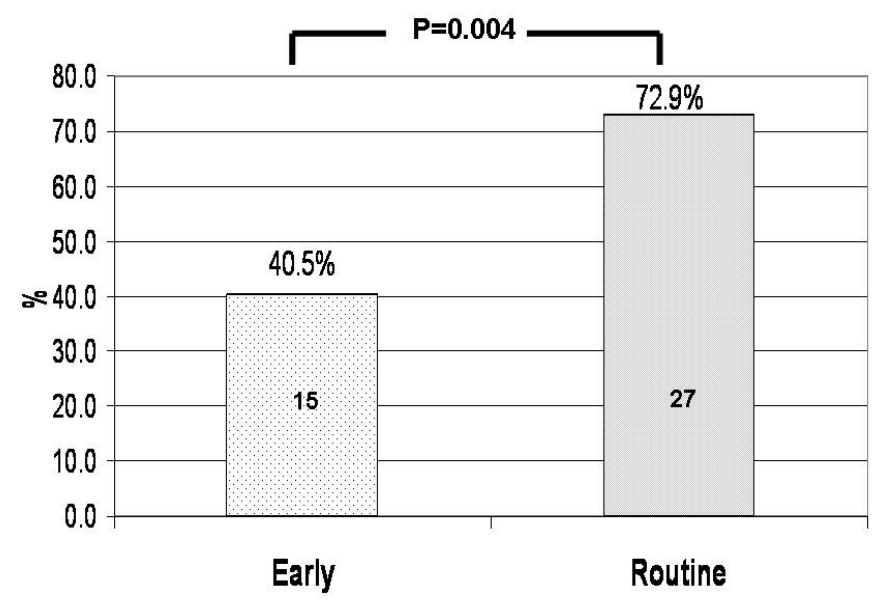

Figure 3. The incidence of UTI between early and routine stent removal group. Absolute risk reduction of UTI in early removal group was $32.4 \%$; $95 \%$ CI 11.1 to $53.7 ; \mathrm{P}=0.004$ by intention to treat analysis. 


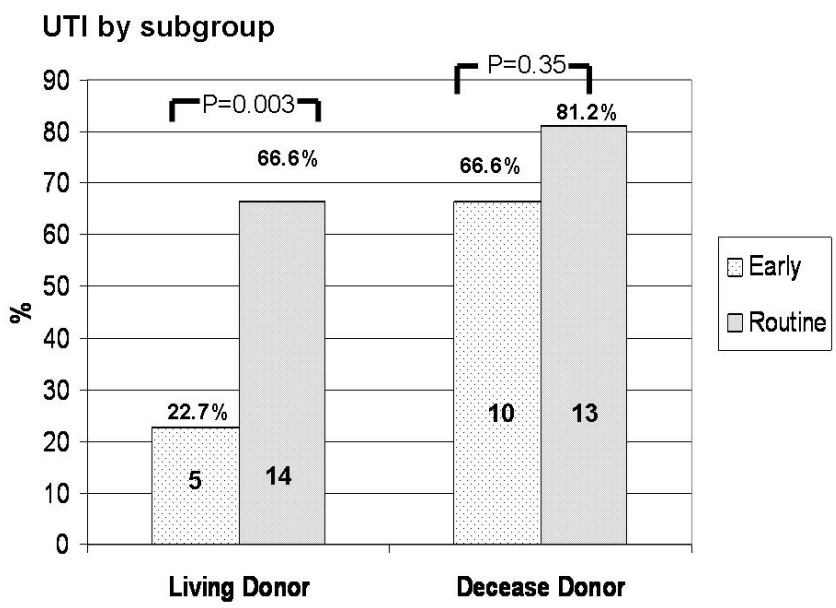

Figure 4. Incidence of UTI by type of donor. Benefit in reduction of UTI of early remove stent was $43.9 \%(95 \%$ CI 17.2 to 70.6 ; $\mathrm{P}=0.004$; ITT $)$ for living donor and $14.5 \%(95 \% \mathrm{CI}$ -15.9 to $45.1 ; \mathrm{P}=0.35$; ITT) for decease donor subgroup respectively ITT=intension to treat.

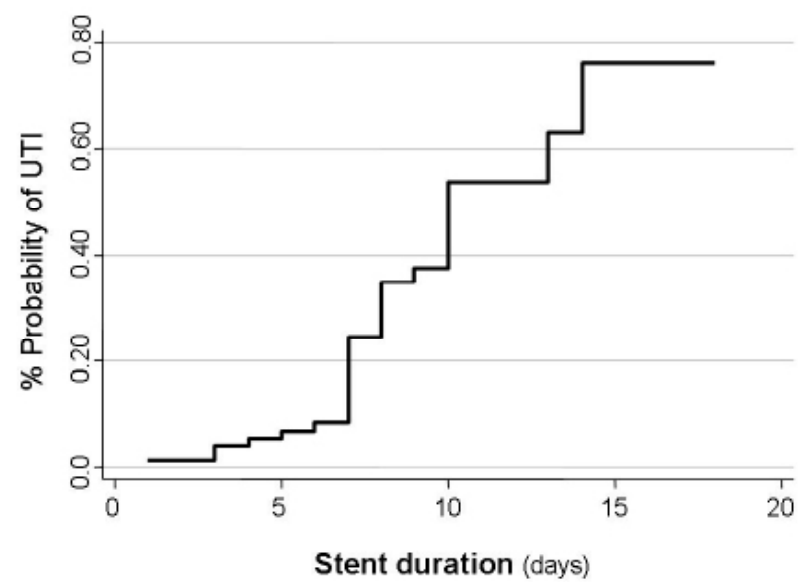

Figure 5. Duration of stent and probability of UTI. Using Nelson-Aalen cumulative hazard estimate.

group, with median difference of 8 days (18 vs. 26 days; $\mathrm{P}=0.01)$ in living donor and 1.5 days ( 26 vs. $27.5 ; \mathrm{P}=0.87$ ) in deceased donor. The incidence of positive stent culture for bacterial organism was much more in routine removal group $(10 / 37 ; 27 \%$ vs. $6 / 37 ; 16.2 \% ; \mathrm{P}=0.25)$. eGFR by 4 variable MDRD equation at discharge seem to be higher in early removal group ( $\left.65.5 \mathrm{vs.} 59.2 \mathrm{ml} / \mathrm{min} / 1.73 \mathrm{~m}^{2}\right)$ but did not reach statistical significance $(\mathrm{p}=0.17)$

Urologic complications occur in 6 of 74 patients (8.1\%), 4 patients in the early removal group and 2 patients in the routine removal group that were not statistically significant between two groups. $(P=0.39$ for intention to treat). When analyzed as per protocol, two urologic complications occurred in the early removal group and four in the routine removal group, $\mathrm{P}=0.47$ ). All urologic complications involved leakage and required surgery. Two of them develop complications when ureteric stent was retained. Most urinary leakage patients (4 in 6) occurred in diabetes patients and (5 in 6) within 2 week postoperatively.

Prolonged stent duration is associated with probability of UTI (Figure 5). By univariate analysis, identifiable risk factors of UTI were
Table 2. Risk factors for develop UTI on univariate and multivariate analysis.

\begin{tabular}{|c|c|c|c|c|}
\hline Factors* & $\begin{array}{c}\text { Crude HR } \\
(95 \% \text { CI) }\end{array}$ & $\mathbf{P}$ & $\begin{array}{c}\text { Adjust HR } \\
(95 \% \text { CI) }\end{array}$ & $\mathbf{P}$ \\
\hline \multicolumn{5}{|c|}{ Stent removal } \\
\hline Early & 1 & & 1 & \\
\hline Routine & $1.89(1-3.57)$ & 0.04 & $2.05(1.08-3.88)$ & 0.026 \\
\hline \multicolumn{5}{|l|}{ Sex } \\
\hline Male & 1 & & 1 & \\
\hline Female & $3.07(1.64-5.74)$ & $<0.001$ & $3.59(1.89-6.81)$ & $<0.001$ \\
\hline \multicolumn{5}{|c|}{ Diabetes Mellitus } \\
\hline Yes & 1 & & & \\
\hline No & $1.76(0.74-4.2)$ & 0.19 & - & \\
\hline \multicolumn{5}{|l|}{ Donor type } \\
\hline Living & 1 & & & \\
\hline Decease & $1.91(1.04-3.51)$ & 0.03 & - & \\
\hline \multicolumn{5}{|l|}{ Induction } \\
\hline None & 1 & & 1 & \\
\hline Basiliximab & $2.38(1.28-4.41)$ & 0.006 & $1.56(1.16-2.18)$ & 0.004 \\
\hline \multicolumn{5}{|l|}{ Maintainance } \\
\hline Cyclosporine & 1 & & & \\
\hline Tacrolimus & $1.56(0.84-2.88)$ & 0.15 & - & \\
\hline \multicolumn{5}{|c|}{ Graft function } \\
\hline Immediate & 1 & & & \\
\hline Delay & $1.94(1.03-3.66)$ & 0.03 & - & \\
\hline \multicolumn{5}{|l|}{\begin{tabular}{|l|} 
Donor pyuria \\
\end{tabular}} \\
\hline No & 1 & & & \\
\hline Yes & $1.59(0.73-3.45)$ & 0.23 & - & \\
\hline
\end{tabular}

*By Cox's proportional hazards models HR = hazard ratio

routine stent removal, female sex, Basiliximab for induction, decease donor and delayed graft function. However, Cox proportional hazard regression found that only routine stent removal, female sex and Basiliximab induction therapy were significant risk factors of UTI (multivariate analysis) (Table 2).

\section{Discussion}

Urinary tract infection is common infection after post-operative kidney transplantation despite use of antibiotics for prophylaxis $(52.7 \%$ in this study). This RCT supported the reduction of UTI through early ureteric stent removal. Other benefits of early ureteric stent removal included shortening the length of hospital stay while the incidence of urological complications. Because kidney transplantation is a procedure that interferes with normal barriers in the urinary system, longer retention of instruments (bladder catheter, ureteric stent) in the urinary tract increases the risk of UTI. Moreover, the stent eliminates antireflux mechanism in sub muscular anastomosis site which leads to ascending infection. We also found an association between the duration of stent placement and the probability of UTI. Other factors that affected the risk of UTI were female gender and Basiliximab induction therapy. The benefits of early ureteric stent removal in UTI were predominately in the living related group but there were few benefits in the decreased donor group. Reasons for this finding were unclear. However, we have found that the incidence of UTI was higher in deceased donor than living donor group (74.1 VS 45.2\%). This high incidence may be related to more aggressive immunosuppressive for induction (25.5\% in living donor group and $54.8 \%$ in deceased donor group), donor derived infections, and delayed graft function. The latter was supported by the finding that delayed graft function was a risk factor of UTI in our study and occurred more often in deceased donor than living kidney transplanted recipients. 
It was formerly believed that prolonged stent retention can reduce ureteric obstruction or leakage. However, this study found no significant difference in urologic complications between patients in early and routine groups. Retaining ureteric stent for one week was the optimal time to prevent urologic complication and also decrease risk of UTI because (I) ureterovesical anastomosis was healed (ii) discharge from the drain dried out (iii) bladder catheter had been removed and (iv) probability to develop UTI rapidly increase at day 7 to 9 postoperatively (Figure 5).

The clear benefits of ureteric stent in kidney transplantation were shown in 2 meta-analyses [12,23]. Ureteric stent can reduce urologic complication but increase a risk of UTI when compared with no stent. One randomized control study used $6 \mathrm{Fr}, 12 \mathrm{~cm}$ double J stent for 7-10 days with cotrimoxazole prophylaxis in both living and deceased donor kidney transplants [16]. They found no significant difference incidence of UTI in the stent and without stent groups. Another study [15] used $5 \mathrm{Fr}, 20 \mathrm{~cm}$ double J stent for 14 days with intravenous amoxicillin 5 days in only living donor kidney transplants. This study found more incidents of UTI in the stent group compared to the no stent group. In common, both studies showed that the use of stent did not lead to reduced urologic complications. However, one cost-effectiveness analysis suggested that ureteric stent should be routinely used in kidney transplant recipients [14].

Our study is a randomized control trial to support the view that early ureteric stent removal can reduce UTI in kidney transplant recipients. The association of stent duration and UTI had been investigated in two previous studies $[24,25]$. The results showed that retaining a stent more than 30 days will increase risk of UTI [24]. In contrast, another study [25] showed that shortening the duration of external stent for 5-day was safe and can decrease UTI when compared with histological control.

In this study, we do not aim to investigate the impact of antibiotic prophylaxis and duration of bladder catheter in the reduction of UTI. Hence, all enrolled patients receive sulfamethoxazole/trimethoprim prophylaxis and a fixed duration of bladder catheter insertion. Our results have shown that shortening the duration of ureteric stent shows benefits in reduction of UTI (number needed to treat $=3$ ). Shortening the stent duration also shortens the length of hospital stay to 8 days (30\%) per patient (data not shown).

Our findings that urologic complications occurred in $10.8 \%$ in early removal group and $5.4 \%$ in routine removal group need to be discussed. However, in our study early ureteric stent removal do not increase urologic complications when compare with routine stent removal. This is due to two important findings in our study. First, we have observed that 2 of 6 urologic complications occurred while the stent was still retained. Second, urologic complication occurred much more in the routine removal group ( 2 in the early group and 4 in the routine group). The results of our study should support the strategy of early ureteric stent removal. This is a simple strategy and do not need more equipment and technique. It can help to reduce UTI, length of hospital stay and save cost.

Our study had certain limitations. One issue is that the incidence of UTI in our study appears to be high. This is related to several reasons. First, we have included asymptomatic bacteriuria in our study design. Second, we have a practice protocol to take at least five urine cultures in the first two weeks and then twice weekly until the patients are discharged. Third, nearly one-seventh of kidney graft in our deceased donors already had pyuria before transplantation, which could induce donor-derived infection (data not shown). Fourth, we have studied the incidence of UTI in the first two months after kidney transplantation which is the peak period that UTI can occur. Finally, it should be emphasized that this investigation is a single center study. The incidence of UTI may vary among each center and may lead to differences in percentage of UTI reduction among different center

\section{Conclusion}

Shortening the duration of ureteric stent from 15 to 8 days in kidney transplant recipients can effectively reduce the incidence of UTI. This strategy can decrease length of hospital stay and do not increase urologic complications. However, the benefits in reduction of UTI from this approach may be different due to varying practice to monitor urine culture for a diagnose of UTI among each transplant center.

\section{Acknowledgements}

The authors would like to thank Mrs. Sasivimol Rattanasiri, PhD. for the assistance as statistical consultant and Thai Transplantation Society for funding of the study.

\section{References}

1. Alangaden GJ (2006) Infectious complications after kidney transplantation: current epidemiology and associated risk factors. Clin Transplant 20: 401-409.[Crossref]

2. Karakayali H, Emiroglu R, Arslan G, Bilgin N, Haberal M (2001) Major infectious complications after kidney transplantation. Transplant Proc 33: 1816-1817.

3. Chuang P, Parikh CR, Langone A (2005) Urinary tract infections after renal transplantation: a retrospective review at two US transplant centers. Clin Transplant 19: 230-235.

4. Martinez-Marcos F, Cisneros J, Gentil M, Algarra G, Pereira P, et al. (1994) Prospective study of renal transplant infections in 50 consecutive patients. Eur J Clin Microbiol Infect Dis 13: 1023-1028.[Crossref]

5. Pelle G, Vimont S, Levy PP, Hertig A, Ouali N, Chassin C, et al. (2007) Acute pyelonephritis represents a risk factor impairing long-term kidney graft function. $\mathrm{Am} \mathrm{J}$ Transplant 7: 899-907.[Crossref]

6. Ciszek M, Pạczek L, Bartłomiejczyk I, Mucha K (2006) Urine cytokines profile in renal transplant patients with asymptomatic bacteriuria. Transplantation 81: 1653-1657.

7. Fiorante S, López-Medrano F, Lizasoain M, Lalueza A, Juan RS, et al. (2010) Systematic screening and treatment of asymptomatic bacteriuria in renal transplant recipients. Kidney International 78: 774-81.[Crossref]

8. John U (2006) High prevalence of febrile urinary tract infections after paediatric renal transplantation. Nephrol Dial Transplant 21: 3269-74.[Crossref]

9. Lorenz EC, Cosio FG (2010) The impact of urinary tract infections in renal transplant recipients. Kidney International 78: 719-21.[Crossref]

10. Giral M, Pascuariello G, Karam G, Hourmant M, Cantarovich D, et al. (2002) Acute graft pyelonephritis and long-term kidney allograft outcome. Kidney Int 61: 1880-1886. [Crossref]

11. Ranganathan M, Akbar M, Ilham MA, Chavez R, Kumar N, et al. (2009) Infective complications associated with ureteral stents in renal transplant recipients. Transplant Proc 41: 162-164.

12. Wilson CH, Bhatti AA, Rix DA, Manas DM (2005) Routine intraoperative ureteric stenting for kidney transplant recipients. Cochrane Database Syst Rev 4: CD004925.

13. Mangus RS, Haag BW (2004) Stented versus nonstented extravesical ureteroneocystostomy in renal transplantation: A metaanalysis. Am J Transplant 4: 1889-96.

14. DuBay DA, Lynch R, Cohn J, Ads Y, Punch JD, Pelletier SJ, et al. (2007) Is routine ureteral stenting cost-effective in renal transplantation? J Urol 178: 2509-2513. [Crossref]

15. Osman Y, Ali-El-Dein B, Shokeir AA, Kamal M, El-Din AB (2005)Routine insertion of ureteral stent in live-donor renal transplantation: is it worthwhile? Urology 65: 867871.[Crossref] 
16. Dominguez J, Clase CM, Mahalati K, MacDonald AS, McAlister VC, et al. (2000) Is routine ureteric stenting needed in kidney transplantation? A randomized trial. Transplantation 70: 597-601.

17. Kumar A, Kumar R, Bhandari M (1998) Significance of routine JJ stenting in living related renal transplantation: a prospective randomised study. Transplant Proc 30: 2995-2997.

18. Guleria S, Agarwal S, Kumar R, Khazanchi RK, Agarwal SK, et al. (1998) The double $\mathrm{J}$ stent: Its impact on the urological complications in live- related renal transplantation. Indian Journal of Urology 14: 101-104.

19. Benoit G, Blanchet P, Eschwege P, Alexandre L, Bensadoun H, et al. (1996) Insertion of a double pigtail ureteral stent for the prevention of urological complications in renal transplantation: a prospective randomized study. J Urol 156: 881-884.

20. Pleass HC, Clark KR, Rigg KM, Reddy KS, Forsythe JL, et al. (1995) Urologic complications after renal transplantation: a prospective randomized trial comparing different techniques of ureteric anastomosis and the use of prophylactic ureteric stents. Transplant Proc 27: 1091-1092.
21. Bassiri A, Amiransari B, Yazdani M, Sesavar Y, Gol S (1995) Renal transplantation using ureteral stents. Transplant Proc 27: 2593-2594.[Crossref]

22. Levey AS, Bosch JP, Lewis JB, Greene T, Rogers N, et al. (1999) A more accurate method to estimate glomerular filtration rate from serum creatinine: a new prediction equation. Modification of Diet in Renal Disease Study Group. Ann Intern Med 130: 461-470.

23. Mangus RS, Haag BW (2004) Stented versus nonstented extravesical ureteroneocystostomy in renal transplantation: a metaanalysis. Am J Transplant 4: $1889-1896$

24. Tavakoli A, Surange RS, Pearson RC, Parrott NR, Augustine T, et al. (2007) Impact of stents on urological complications and health care expenditure in renal transplan recipients: results of a prospective, randomized clinical trial. J Urol 177: 2260-2264.

25. Minnee RC, Bemelman FJ, Laguna Pes PP, ten Berge IJ, Legemate DA, et al. (2009) Effectiveness of a 5-day external stenting protocol on urological complications after renal transplantation. World J Surg 33: 2722-2726.

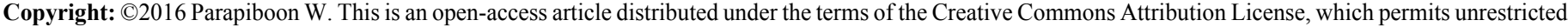
use, distribution, and reproduction in any medium, provided the original author and source are credited. 